\title{
Indicadores de qualidade dos solos na microbacia do Ribeirão Extrema, Distrito Federal: Parte II $^{1}$
}

\author{
Wendel N. M. Lago ${ }^{2}$, Marilusa P. C. Lacerda ${ }^{3}$ \& Marina R. B. Neumann ${ }^{3}$
}

\begin{abstract}
RESUMO
O uso agrícola cada vez mais intensivo dos solos do Distrito Federal pode comprometer a qualidade destes e desencadear problemas ambientais na região. Diante de tal fato, o objetivo deste trabalho foi o estudo de indicadores de qualidade dos solos (QS) em áreas sob plantio direto (PD), com manejos diversificados (rotação milho-soja e sucessão feijão-sorgo) na microbacia do Ribeirão Extrema, Distrito Federal. Densidade do solo (Ds), grau de floculação (GF), teor de matéria orgânica (MO), capacidade de troca catiônica (CTC), respiração basal (Rmic) e carbono da biomassa microbiana (Cmic) constituíram os atributos de QS avaliados. Para execução das análises estatísticas utilizou-se o software estatístico Statistics Analysis System (SAS) e foi realizada a análise de variância (ANOVA), seguida de teste de comparação de médias pelo método de Tukey. Verificou-se que parte dos indicadores de QS avaliados foi influenciada pelos diferentes tipos de manejo estudados (Ds, MO e Cmic), enquanto outros não se mostraram sensíveis aos mesmos (GF, CTC e Rmic). Foi constatada correlação positiva entre MO e CTC dos solos, em ambos os manejos investigados, o que destaca a importância do sistema de plantio direto na melhoria dos atributos químicos dos solos.
\end{abstract}

Palavras-chave: sustentabilidade agrícola, atributos físicos do solo, atributos químicos do solo, atributos biológicos do solo

\section{Soil quality indicators at the Riberão Extrema watershed, Distrito Federal: Part II}

\begin{abstract}
The intensively increasing agricultural use of Distrito Federal soils may compromise their quality and trigger environmental problems in the region. Given this fact, the objective of this work was to study the soil quality (SQ) indicators, in areas under no tillage (PD), with diversified managements (corn-soybean rotation and bean-sorghum succession), at the Riberão Extrema watershed, Distrito Federal. Soil bulk density (Ds), flocculation index (GF), organic matter (MO), cation exchange capacity (CTC), microbial respiration (Rmic) and microbial biomass carbon (Cmic) were the attributes of SQ evaluated. Statistical analysis was performed using the statistical software Statistics Analysis System (SAS) and consisted of analysis of variance (ANOVA) followed by Tukey test for comparison of means. Results show that some of the evaluated SQ indicators were affected by different types of soil management under evaluation (Ds, $\mathrm{Cmic}$ and $\mathrm{MO}$ ), while others were not sensitive to them (GF, CTC and Rmic). Positive correlation was found between $\mathrm{MO}$ and CTC of the soils in both investigated treatments, highlighting the importance of no tillage system on the chemical properties of soil.
\end{abstract}

Key words: agriculture sustainability, physical soil attributes, chemical soil attributes, biological soil attributes 


\section{INTRODUÇÃO}

Expressivos incrementos de rendimento e produção, notadamente nas culturas de grãos, são evidenciados pela agricultura brasileira, na última década. A contínua evolução deste panorama exige constantes tomadas de decisão para a manutenção e preservação da qualidade dos recursos edáficos. Ante este cenário erguem-se premissas de conservação da qualidade dos solos, assim como a busca pela utilização racional e sustentável dos mesmos.

A qualidade do solo (QS), segundo Doran \& Parkin (1994), pode ser conceituada como a capacidade desse recurso em exercer várias funções dentro dos limites do uso da terra e do ecossistema visando sustentar a produtividade biológica, manter ou melhorar a qualidade ambiental e contribuir para a saúde das plantas, dos animais e humana. Segundo esses autores, a QS pode ser medida por meio da quantificação de alguns atributos dos solos, ou seja, de propriedades físicas, químicas e biológicas, que possibilitem o monitoramento de mudanças, a médio e longo prazo, no estado de qualidade desses solos.

Para Goedert (2005), a escolha de indicadores ou atributos a serem quantificados deve considerar, entre outros, os seguintes aspectos: facilidade de medição, sensibilidade a mudanças e limites claros entre condições de sustentabilidade e de não sustentabilidade. $\mathrm{O}$ autor propôs um conjunto mínimo de indicadores da qualidade em Latossolos argilosos tropicais, no qual níveis de sustentabilidade são quantificados a partir dos atributos mais frequentemente avaliados em pesquisas científicas envolvendo a qualidade dos solos brasileiros.

No Brasil, os solos sob Cerrado apresentam, em geral, condições físicas favoráveis à agricultura e vêm sendo gradativamente explorados com culturas anuais, pastagens e, mais recentemente, reflorestamentos. A mudança da vegetação natural para sistema de exploração agropecuária provoca alterações profundas nos atributos do solo. Quando uma área de vegetação nativa de Cerrado, por exemplo, é convertida em pastagem ou área de cultivo de grãos, os atributos químicos e microbiológicos do solo são alterados (Costa et al., 2006; Carneiroet al., 2009). Lourente et al. (2011) verificaram, ao avaliar atributos de qualidade de um Latossolo Vermelho em áreas de Cerrado, que a substituição da vegetação nativa por sistemas de cultivo pode causar alterações significativas nos atributos químicos do solo, já no primeiro ano de implantação.

O Distrito Federal (DF) vem apresentando elevada expansão das áreas agrícolas, algumas vezes sem o devido planejamento e monitoramento das condições edáficas, podendo desencadear problemas na qualidade dos solos e consequente degradação dos recursos naturais a eles vinculados. Neste contexto há uma série de trabalhos envolvendo a avaliação da qualidade de Latossolos no DF, dentre eles os desenvolvidos por Costa et al. (2006), Araújo et al. (2007) e Netto (2009). Esses autores chegaram, unanimemente, a várias conclusões que se referem às alterações sofridas pelos atributos de qualidade dos solos sob estudo, conforme os diferentes usos avaliados.

A microbacia do Ribeirão Extrema integra a bacia do Rio Preto, no DF, sendo esta um importante referencial no cenário nacional no que diz respeito ao processo de ocupação e utilização de seus recursos, tendo-se em conta sua importância para a bacia hidrográfica do Rio São Francisco (Carneiro et al., 2007). Com cerca de 70.000 ha destinados à agricultura, a bacia do Rio Preto é responsável por cerca de $80 \%$ da produção agrícola do DF. Dentre os principais produtos comercializados na região se destaca o milho que atende, basicamente, ao mercado interno do DF e entorno; os hortifrutigranjeiros, que atendem ao mercado interno mas também são comercializados fora do DF; a soja, que atende ao mercado nacional e também é exportada e o feijão, que atende parte da demanda do mercado nacional (Carneiro et al., 2007).

A avaliação das alterações ocorridas em propriedades dos solos em função do seu uso e manejo, assume grande importância prática uma vez que o entendimento das modificações ocorridas nas propriedades químicas, físicas e biológicas, decorrentes do seu cultivo, pode fornecer elementos para produção em bases sustentáveis (Canellas et al., 2003; Rangel \& Silva, 2007; Costa et al., 2008; Carneiro et al., 2009).

Neste contexto, o presente trabalho objetiva estudar os indicadores de qualidade dos solos em áreas ocupadas por usos e manejos agrícolas diversificados na microbacia do Ribeirão Extrema, Distrito Federal, visando verificar a sustentabilidade dos agroecossistemas nesta microbacia, de relevância agrícola para o DF.

\section{MATERIAL E MÉTODOS}

A microbacia do Ribeirão Extrema (Figura 1) localiza-se entre as latitudes $15^{\circ} 41^{\prime} 80^{\prime}$ ' S e $15^{\circ} 51^{\prime} 60^{\prime \prime}$ S e as longitudes $47^{\circ} 32^{\prime}$ 30 " W e $47^{\circ} 22^{\prime} 47^{\prime}$ ' W, na porção leste do Distrito Federal, DF.

$\mathrm{Na}$ área de estudo o clima é considerado Tropical Aw e Tropical de Altitude Cwa, de acordo com a classificação climática de Köppen. A precipitação média anual do DF atinge 1.300 mm, com distribuição irregular (CODEPLAN, 1984)

Na microbacia do Ribeirão Extrema há predomínio de Latossolos Vermelhos. São solos espessos, álicos e fortemente ácidos, pouco férteis, com fraca distinção entre os horizontes. A vegetação associada é composta, geralmente, por Cerrado e Cerradão. Ocorrem, sudordinadamente, Cambissolos, Latossolos Vermelho-Amarelos, Solos Hidromórficos e Neossolos Quartzarênicos (EMBRAPA, 1978).

Para o estudo dos indicadores de QS foram selecionadas duas áreas de um hectare cada, ambas submetidas ao sistema de plantio direto (PD), sob Latossolo Vermelho, denominadas Área I, com uso mais conservador do solo e Área II, com uso mais intensivo do solo.

A Área I apresenta o sistema de PD com rotação entre as culturas de milho (Zea mays) e soja (Glycine max) na estação chuvosa, permanecendo em pousio na estação seca, ao longo dos últimos 15 anos.

Na Área II, sob sistema de PD com sucessão de culturas adota-se, repetitivamente, dentro do mesmo ano agrícola, também por 15 anos, o cultivo anual de feijão (Phaseolus vulgaris), com plantio sequencial de sorgo granífero (Sorghum bicolor), ambos na estação chuvosa. 

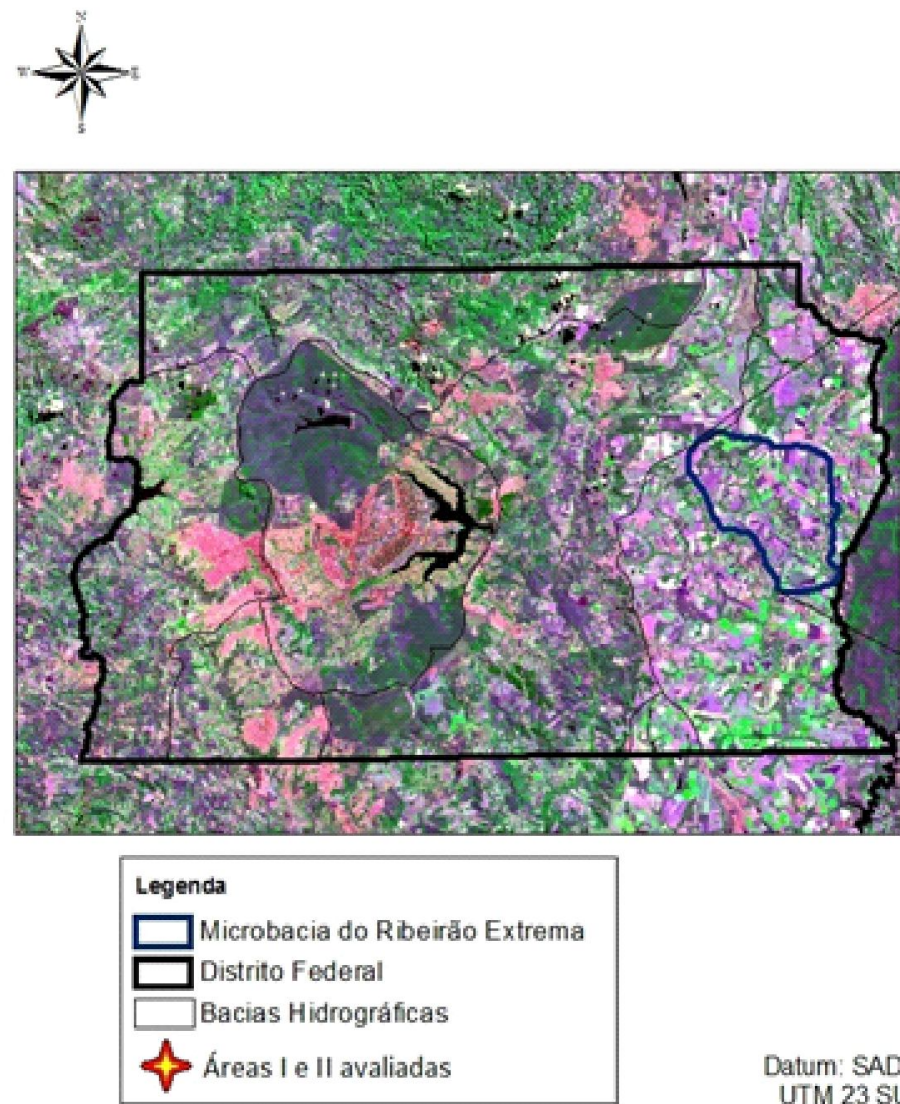

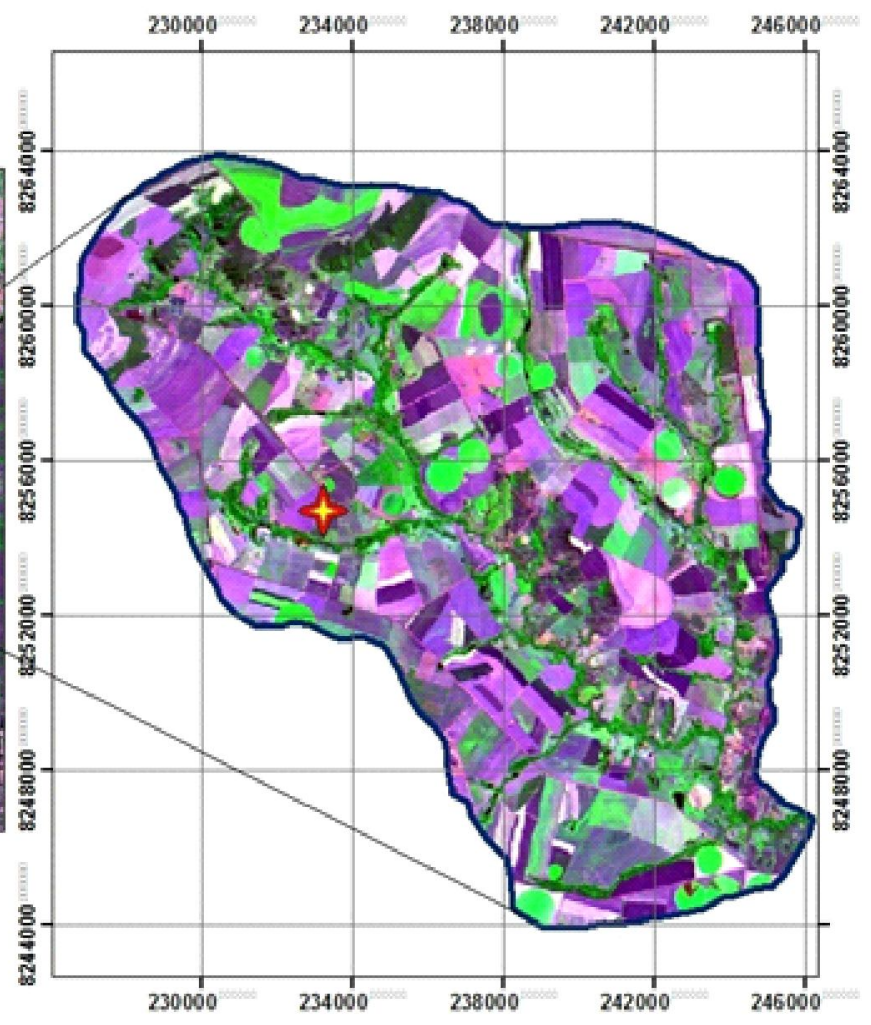

Datum: SAD 69 UTM 23 SUL

Figura 1. Imagem orbital LANDSAT-TM5 (Junho/2010) da microbacia do Ribeirão Extrema, DF

As áreas vêm sendo utilizadas pela agricultura desde 1986, sendo o plantio convencional originalmente implantado e posteriormente suplantado pelo sistema de plantio direto. Em ambas as áreas se efetuam, anualmente, a correção da acidez com aplicação de calcário dolomítico e a manutenção da fertilidade, por meio de fertilização química com NPK + micronutrientes. Nos últimos dois anos anteriores à data de coleta de amostras para este trabalho, em maio de 2010, foram efetuados procedimentos de escarificação em ambas as áreas em virtude de compactação superficial acentuada. Trata-se de áreas com histórico de intensa atividade antrópica, cujos solos foram exaustivamente utilizados.

Tais áreas foram devidamente georreferenciadas assim como os locais de coleta de amostras para o estudo dos indicadores de QS, por meio de GPS de navegação do tipo Garmin MAP 60CSX e as coordenadas geográficas foram implementadas no programa ArcGIS 9.1.

Estabeleceu-se uma malha amostral para cada área investigada de um hectare, com nove pontos equidistantes entre si $(50 \mathrm{~m})$, considerados repetições para a coleta de amostras em duas profundidades $(0-10$ e 10-20 cm) dentro de um raio de dois metros a partir de cada ponto amostral.

Para a avaliação dos atributos químicos e biológicos de QS foram coletadas amostras compostas, constituídas de cinco subamostras, com cerca de $1 \mathrm{~kg}$, devidamente homogeneizadas. As amostras destinadas às análises físicas e químicas foram secadas ao ar, sob sombreamento, com posterior tamisamento em peneira de $2 \mathrm{~mm}$, para obtenção da fração TFSA.
As amostras indeformadas, destinadas às análises da densidade do solo, foram coletadas por meio do Método do Anel Volumétrico, com $100 \mathrm{~cm}^{3}$ de volume interno, com três repetições por ponto amostral.

Efetuou-se a classificação dos solos, das áreas de estudo, até o quarto nível categórico do SiBCS (EMBRAPA, 2006) por meio de análises morfológicas de acordo com Santos et al. (2005), com análises químicas e físicas em auxílio à classificação segundo metodologias descritas em EMBRAPA (1997). Enfatizou-se a classificação textural dos solos uma vez que esta propriedade pode interferir nos atributos de qualidade dos solos selecionados para estudo.

Os indicadores físicos analisados foram grau de floculação (GF) e densidade do solo (Ds). Capacidade de troca catiônica (CTC) e teor de matéria orgânica (MO) foram os indicadores químicos de QS selecionados para o estudo. Esses indicadores foram analisados segundo procedimentos descritos em EMBRAPA (1997). Os indicadores biológicos avaliados foram respiração basal microbiana (Rmic) e carbono da biomassa microbiana (Cmic). A respiração basal microbiana (Rmic) foi calculada a partir da metodologia adotada por Alef \& Nannipieri (1995), com a quantificação do teor de C-CO $\mathrm{CO}_{2}$ liberado das amostras de solo, ao longo de sete dias. Para determinação do carbono da biomassa microbiana (Cmic) recorreu-se ao método CFE (clorofórmio - fumigação - extração), descrito por Vance et al. (1987).

As análises estatísticas foram realizadas utilizando-se o software estatístico Statistics Analysis System (SAS) e se 
constituíram de análise de variância (ANOVA) em relação ao tratamento (Áreas I e II), repetições (nove), profundidades (010 e $10-20 \mathrm{~cm}$ ) e interação tratamento*profundidade, seguida de teste de média Tukey, com posterior análise dos resultados a 1 ou a $5 \%$ de probabilidade, conforme a sensibilidade do método para cada atributo de qualidade do solo estudado (GF, Ds, MO, CTC, Rmic, Cmic). Quando a ANOVA não foi considerada significativa em relação à interação tratamento* profundidade, o teste Tukey foi realizado a partir das médias dos atributos avaliados em cada uma das áreas amostrais.

Valores discrepantes observados entre as nove repetições em cada área amostral nos ensaios laboratoriais dos atributos biológicos de qualidade do solo foram eliminados por meio de filtros estatísticos. Ensaios estatísticos por meio de Correlações de Pearson foram executados para constatação de possíveis interações entre os atributos de QS avaliados.

\section{RESULTADOS E DISCUSSÃO}

Associada às análises químicas e físicas, a análise morfológica permitiu a classificação dos solos estudados nas Áreas I e II, no quinto nível categórico do SiBCS (EMBRAPA, 2006), em Latossolos Vermelhos Distróficos típicos muito argilosos. Na caracterização morfológica destacaram-se, nos horizontes Bw, a cor de Münsel vermelha ( $\geq 2,5$ YR), a estrutura forte muito pequena granular, originando porosidade elevada e consistência friável, em condições de solo úmido. A textura foi classificada como muito argilosa cujos teores de argila oscilaram entre 630 e $710 \mathrm{~g} \mathrm{~kg}^{-1}$ na Área I e entre 620 e $730 \mathrm{~g} \mathrm{~kg}^{-1}$ na Área II. As análises químicas nos horizontes A, que correspondem aos horizontes estudados dos solos das Áreas I e II, mostraram $\mathrm{pH}$ corrigido pela calagem variando de 5,5 a 6,0, capacidade de troca catiônica (CTC) baixa, variando de 7,0 a $10,0 \mathrm{cmol}_{\mathrm{c}} \mathrm{dm}^{-3}$, saturação por alumínio (m) nula, por efeito da calagem, e teor de matéria orgânica (MO) médio a alto, variando de 36,0 a 49,0 $\mathrm{g} \mathrm{kg}^{-1}$.

Assim, os solos avaliados nas Áreas I e II foram considerados semelhantes, inclusive com relação à textura, uma vez que vários atributos utilizados para avaliação da qualidade do solo podem ser alterados em função da classe textural, com destaque para o grau de floculação e propensão à compactação em Latossolos (Carvalho Jr. et al., 1998 e Silva et al., 2000).

Os resultados das análises laboratoriais dos atributos físicos, químicos e biológicos de QS avaliados estão dispostos na Tabela 1. Valores discrepantes detectados entre os atributos biológicos de QS foram eliminados por meio de filtros estatísticos.

A análise estatística, correspondente ao teste de Tukey, foi realizada nos valores médios em relação aos tratamentos (Áreas I e II) e às profundidades avaliadas (0-10 e 10-20 cm) para todos os atributos estudados a 1 e $5 \%$ de probabilidade, visto que a análise de variância realizada com os valores obtidos para os atributos estudados de QS, não detectou diferenças estatísticas significativas nos valores de interação entre tratamento e profundidade.

O GF variou de 49,20 a 59,15\% na Área I e entre 50,70 e 61,42\% na Área II (Tabela 1); no entanto, estatisticamente, os referidos valores não mostraram diferenças significativas nos tratamentos (Área I e II) nem entre as profundidades estudadas (0-10 e 10-20 $\mathrm{cm})$. O valor médio do GF foi de 53,88\% na Área I e 54,79\% na Área II, dentro, portanto, do padrão de sustentabilidade para GF em Latossolos tropicais, de textura argilosa, proposto por Goedert (2005), ou seja, acima de 50\%. Entende-se, assim, que tanto o sistema de PD com rotação de culturas (Área I) quanto o sistema de PD com sucessão de culturas (Área II) influenciaram de forma similar no Grau de Floculação e consequentemente na estabilidade dos agregados dos solos avaliados. Estudando a qualidade de um Latossolo Vermelho submetido aos sistemas de plantio direto e plantio convencional no Distrito Federal, Costa et al. (2006) concluíram que o atributo GF não se diferenciou

Tabela 1. Valores dos atributos físicos, químicos e biológicos de qualidade de solos (QS) avaliados

\begin{tabular}{|c|c|c|c|c|c|c|c|c|c|c|c|c|c|}
\hline \multirow[t]{2}{*}{ Repetição } & \multirow{2}{*}{$\begin{array}{l}\text { Profundidade } \\
\text { (cm) }\end{array}$} & \multicolumn{2}{|c|}{$\begin{array}{c}\text { GF* }^{*} \\
\%\end{array}$} & \multicolumn{2}{|c|}{$\begin{array}{c}\mathrm{Ds}^{*} \\
\mathrm{~g} \mathrm{~cm}^{-3}\end{array}$} & \multicolumn{2}{|c|}{$\begin{array}{c}\text { CTC }^{*} \\
\text { cmol }_{\mathrm{c}} \mathrm{dm}^{-3}\end{array}$} & \multicolumn{2}{|c|}{$\begin{array}{l}\mathrm{MO}^{*} \\
\mathrm{~g} \mathrm{~kg}^{-1}\end{array}$} & \multicolumn{2}{|c|}{$\begin{array}{c}\text { Rmic* }^{*} \\
\mathrm{mg} \mathrm{C} \mathrm{kg}^{-1} \mathrm{~d}^{-1}\end{array}$} & \multicolumn{2}{|c|}{$\begin{array}{c}\mathrm{Cmic}^{*} \\
\mathrm{mg} \mathrm{C} \mathrm{kg-1}\end{array}$} \\
\hline & & $I^{* *}$ & $I^{* *}$ & $I$ & II & I & II & I & II & $I$ & II & I & II \\
\hline \multirow{2}{*}{1} & $0-10$ & 50,74 & 61,53 & 1,15 & 0,89 & 10,1 & 9,0 & 47,0 & 47,0 & 19,72 & - & 138,10 & - \\
\hline & $10-20$ & 53,73 & 56,71 & 1,06 & 0,92 & 8,5 & 7,3 & 37,0 & 34,0 & 42,00 & 46,10 & 80,60 & 27,06 \\
\hline \multirow{2}{*}{2} & $0-10$ & 59,15 & 53,84 & 1,06 & 0,95 & 9,3 & 9,7 & 46,0 & 46,0 & - & 23,63 & 72,92 & 217,36 \\
\hline & $10-20$ & 56,52 & 50,70 & 1,04 & 0,98 & 7,6 & 7,9 & 41,0 & 37,0 & 47,05 & 26,89 & 38,78 & 137,16 \\
\hline \multirow{2}{*}{3} & $0-10$ & 57,74 & 51,56 & 1,09 & 0,90 & 9,6 & 10,0 & 44,0 & 49,0 & 21,42 & 18,10 & - & 128,21 \\
\hline & $10-20$ & 56,33 & 52,85 & 1,10 & 1,05 & 7,7 & 7,5 & 37,0 & 37,0 & 74,45 & - & 39,85 & - \\
\hline \multirow{2}{*}{4} & $0-10$ & 49,23 & 59,09 & 0,99 & 0,99 & 10,3 & 9,5 & 49,0 & 44,0 & - & 21,90 & - & 99,27 \\
\hline & $10-20$ & 55,07 & 53,52 & 1,07 & 1,02 & 7,2 & 7,2 & 36,0 & 33,0 & - & 41,75 & - & 58,38 \\
\hline \multirow{2}{*}{5} & $0-10$ & 50,00 & 56,45 & 0,96 & 0,85 & 9,2 & 10,6 & 49,0 & 49,0 & - & - & 58,80 & 163,49 \\
\hline & $10-20$ & 52,17 & 52,94 & 1,15 & 1,02 & 7,8 & 7,1 & 39,0 & 36,0 & 36,53 & 26,57 & 64,53 & 116,62 \\
\hline \multirow{2}{*}{6} & $0-10$ & 56,92 & 56,06 & 0,96 & 1,13 & 9,3 & 9,1 & 47,0 & 44,0 & 23,40 & - & 137,39 & - \\
\hline & $10-20$ & 49,20 & 55,55 & 1,05 & 1,01 & 7,2 & 6,9 & 37,0 & 33,0 & 13,71 & 45,18 & 41,96 & 163,82 \\
\hline \multirow{2}{*}{7} & $0-10$ & 55,38 & 61,42 & 0,91 & 0,90 & 9,2 & 9,8 & 46,0 & 44,0 & 37,64 & 32,93 & - & 218,82 \\
\hline & $10-20$ & 54,41 & 51,38 & 1,05 & 0,98 & 7,8 & 8,6 & 37,0 & 36,0 & - & - & - & 133,68 \\
\hline \multirow{2}{*}{8} & $0-10$ & 59,09 & 54,41 & 0,97 & 0,86 & 9,4 & 9,3 & 51,0 & 41,0 & - & 29,46 & 116,55 & 120,97 \\
\hline & $10-20$ & 52,17 & 52,05 & 1,01 & 0,97 & 8,2 & 7,3 & 39,0 & 33,0 & 32,34 & 21,65 & 46,43 & 66,06 \\
\hline \multirow{2}{*}{9} & $0-10$ & 50,74 & 56,06 & 0,92 & 0,85 & 9,8 & 10,0 & 49,0 & 47,0 & 21,76 & 38,46 & - & - \\
\hline & $10-20$ & 51,42 & 55,55 & 1,05 & 0,99 & 8,0 & 8,9 & 41,0 & 36,0 & 79,93 & 26,75 & 63,86 & - \\
\hline
\end{tabular}

$\left(^{\star}\right)$ GF = Grau de Floculação; Ds = Densidade do solo; CTC = Capacidade de Troca Catiônica; M0 = Matéria Orgânica; Rmic = Respiração Basal Microbiana; Cmic = Carbono da Biomassa Microbiana. $\left({ }^{* *}\right)$ Áreas I e II avaliadas 
estatisticamente entre os dois sistemas, sendo este pouco sensível às alterações de manejo. Se em dois sistemas de manejo consideravelmente contrastantes o GF respondeu de forma similar aos dois tratamentos, prevê-se que tal fenômeno ocorra dentro de um mesmo sistema de plantio (PD), ainda que sob manejos distintos (rotação e sucessão), tais como os implantados nas Áreas I e II estudadas.

A Ds apresentou valores variando entre 0,91 e $1,15 \mathrm{~g} \mathrm{~cm}^{-3}$ na Área I e de 0,85 a $1,13 \mathrm{~g} \mathrm{~cm}^{-3}$ na Área II. As análises estatísticas isoladas dos tratamentos (Área I e Área II) e profundidades (010 e $10-20 \mathrm{~cm}$ ) sinalizaram diferenças significativas a $1 \%$ no teste de Tukey, para ambos os fatores de variação (tratamentos e profundidades). Ao se avaliar o valor médio da Ds nas áreas estudadas, ou seja: $1,03 \mathrm{~g} \mathrm{~cm}^{-3}$ na Área I e $0,95 \mathrm{~g} \mathrm{~cm}^{-3}$ na Área II, verifica-se que tanto na Área I como na Área II a Ds se encontra dentro do padrão de sustentabilidade para este atributo em Latossolos tropicais, proposto por Goedert (2005), o qual deve ser inferior a $1,0 \mathrm{~g} \mathrm{~cm}^{-3}$.

Segundo Reichert et al. (2009), valores de densidade do solo superiores a $1,74 \mathrm{~g} \mathrm{~cm}^{-3}$ são considerados críticos. Tanto os solos da Área I quanto da Área II, apresentaram valores médios de Ds abaixo desses valores, não demonstrando, portanto, condições restritivas para o desenvolvimento radicular de culturas agrícolas.

Observa-se que na Área I ocorre maior número de repetições com valores individuais de Ds maiores que $1,0 \mathrm{~g} \mathrm{~cm}^{-3}$, demonstrando maior tendência do tratamento PD com rotação em comprometer a qualidade do atributo em questão.

O valor médio da Ds, discretamente menor na Área II em relação à Área I, pode ter sido influenciado pelos efeitos de uma deposição mais intensa de resíduos vegetais, colaborando com os incrementos de matéria orgânica e consequente redução da Ds, na superfície do solo. Bayer et al. (2003) constataram, ao comparar diferentes sistemas de rotação de culturas sob PD com espécies de cobertura antecedendo o milho no verão, que em 5 anos os estoques de C orgânico da camada arável do solo apresentaram incrementos expressivos nas áreas cultivadas com leguminosas de cobertura em relação ao cultivo de milho após pousio. Portanto, a simples sucessão mais intensiva de culturas proporcionou recuperações significativas dos estoques de matéria orgânica do solo, colaborando com a redução da densidade do solo na Área II.

Há, ainda, de se considerar o maior período da atuação descompactante das raízes do feijão e do sorgo, mais intensivamente cultivados na Área II, quando comparado com a Área I, que permanece em pousio anualmente, por determinado período mais longo. Uma alternativa para melhorar a qualidade estrutural do solo refere-se ao uso de sucessão de culturas com espécies que tenham sistema radicular vigoroso, com capacidade de crescer em solos com alta resistência à penetração, criando poros por onde as raízes da cultura subsequente possam crescer (Silva \& Rosolem, 2001).

Os valores médios da Ds nas profundidades de 0-10 e 10-20 $\mathrm{cm}$ foram de $0,96 \mathrm{e} 1,02 \mathrm{~g} \mathrm{~cm}^{-3}$, respectivamente. Verificou-se, então, na profundidade superficial $(0-10 \mathrm{~cm})$ das Áreas I e II, um valor médio ligeiramente menor de Ds, diferente do que é normalmente observado em áreas cultivadas sob sistemas de plantio direto nos quais a compactação das camadas superficiais é comumente detectada. Em geral, no sistema de plantio direto os solos apresentam, após três a quatro anos, maiores valores de densidade e microporosidade na camada superficial e menores valores de macroporosidade e porosidade total, quando comparados com os solos com o preparo convencional. Isto ocorre sobretudo pelo arranjamento natural do solo não mobilizado e pela pressão provocada pelo trânsito de máquinas e implementos agrícolas, em particular quando realizado em solos argilosos e com teores elevados de umidade (Silveira \& Stone, 2003).

Resultados análogos obtiveram Costa et al. (2006), que não detectaram compactação superficial em um Latossolo Vermelho Distrófico do DF, sob sistema de plantio direto. Silva et al. (2004) observaram que a distribuição da compactação superficial do solo sob sistema de PD ocorre de maneira sistemática, sendo maior nas laterais da lavoura, diminuindo para o centro em função do tráfego de máquinas.

Além da pressão provocada pelo maquinário agrícola, uma provável justificativa para este comportamento incomum da Ds em plantio direto, detectada na profundidade superficial (0$10 \mathrm{~cm}$ ), refere-se ao acúmulo superficial de matéria orgânica e aos procedimentos de escarificação do solo realizados há aproximadamente 2 anos anteriores à data de coleta das amostras de solo para análise.

Para Reinert et al. (2008), a presença de valores reduzidos de densidade do solo na camada superficial de solos sob PD, ocorre em razão da maior densidade de raízes, maior teor de matéria orgânica, ciclos de umedecimento e secagem e do revolvimento parcial no momento da semeadura.

A variação constatada entre os valores de CTC foi de 7,20 a $10,30 \mathrm{cmol}_{\mathrm{c}} \mathrm{dm}^{-3}$ na Área Ie de 6,90 a $10,60 \mathrm{cmol}_{\mathrm{c}} \mathrm{dm}^{-3}$ na Área II (Tabela 1), cuja análise estatística isolada dos tratamentos (Área I e Área II) e profundidades (0-10 e 10-20 cm) mostrou diferença significativa a $1 \%$ no teste de Tukey, apenas para profundidade. $\mathrm{O}$ valor médio da CTC calculado para a Área I foi de $8,67 \mathrm{cmol}_{c} \mathrm{dm}^{-3}$ e de $8,65 \mathrm{cmol}_{c} \mathrm{dm}^{-3}$ para a Área II, não sendo considerados sustentáveis, conforme os padrões estabelecidos por Goedert (2005) para a CTC em Latossolos tropicais de textura argilosa $\left(>10,00 \mathrm{cmol} \mathrm{dm}^{-3}\right)$.

Como diferenças significativas entre os valores médios da CTC nas Áreas I e II não foram constatadas, tal fato demonstra a pouca sensibilidade deste atributo frente aos manejos de rotação e sucessão em sistema de plantio direto.

Já entre as profundidades avaliadas, a de $0-10 \mathrm{~cm}$ apresentou valor médio da CTC de $9,62 \mathrm{cmol}_{\mathrm{c}} \mathrm{dm}^{-3}$, significativamente superior ao valor médio de $7,70 \mathrm{cmol}_{\mathrm{c}} \mathrm{dm}^{-3}$ verificado na profundidade de $10-20 \mathrm{~cm}$. A justificativa pode estar na influência dos teores de MO sobre a CTC nas profundidades analisadas, uma vez que a profundidade de $0-10 \mathrm{~cm}$ apresentou valor médio de MO significativamente superior ao valor obtido na profundidade de $10-20 \mathrm{~cm}$. Este comportamento reflete as tendências de correlação positiva entre CTC e os teores de MO em Latossolos sob plantio direto, conforme resultados encontrados por Araújo et al. (2007).

Os solos tropicais, intensamente intemperizados apresentam, como uma das suas principais características 
químicas, a baixa CTC. Nesses solos o teor de MO tem importância preponderante na CTC efetiva (Bayer et al., 2002).Como a maior proporção da CTC de solos com argilas de baixa atividade é originária de sua fração orgânica, previa-se a influência preponderante dos teores de MO nos valores da CTC dos solos estudados, haja vista tratar-se de latossolos muito evoluídos, nos quais a mineralogia predominante é constituída por sesquióxidos e caulinita (Barbosa \& Lacerda, 2009, Campos et al., 2010), que exercem pouca influência sobre a CTC.

Resultados análogos foram observados por Araújo et al. (2007) que, ao avaliarem a qualidade de um Latossolo no DF sob diferentes usos, verificaram tendências similares na variação dos valores de CTC e dos teores de MO, conforme a profundidade estudada. Os autores observaram redução significativa da CTC, assim como da MO, de acordo com o aumento da profundidade. Costa et al. (2006) também constataram valores de CTC mais elevados na camada de $0-10 \mathrm{~cm}$ em Latossolos sob sistema de plantio direto no DF e vincularam tal diferença à influência dos teores de matéria orgânica que, da mesma forma, foram superiores nas camadas superficiais.

A matéria orgânica (MO) do solo apresentou valores na Área I variando de 36,00 a 51,00 g kg-1 e de 33 a $49 \mathrm{~g} \mathrm{~kg}^{-1}$ na Área II, em que a análise estatística isolada dos tratamentos (Área I e Área II) e profundidades (0-10 e 10-20 cm), mostrou diferença significativa a $1 \%$ no teste de Tukey, para ambos os fatores de variação.

Os valores médios de MO obtidos nas Áreas I e II apresentaram diferenças significativas entre si, com 42,88 $\mathrm{g} \mathrm{kg}^{-1}$ na Área I e 40,33 $\mathrm{g} \mathrm{kg}^{-1}$ na Área II, refletindo a sensibilidade deste atributo frente aos manejos de rotação e sucessão adotados nas áreas de estudo. Os teores mais elevados de MO na Área I podem ser justificados pelo período de pousio entre os cultivos de soja e milho, no sistema de rotação anual adotado nesta área. Supõe-se que, neste período, a matéria orgânica do solo fica menos exposta ao ataque dos microorganismos, proporcionado pela microbiota rizosférica e pela ação descompactante e de revolvimento das raízes, que colaboram com a quebra das estruturas que protegem fisicamente a $\mathrm{MO}$ dos agentes decompositores.

Além disso, o milho cultivado no sistema de rotação da Área I constitui uma cultura que apresenta elevada fitomassa aérea e radicular e auxilia na incorporação de matéria orgânica nos solos. Por se tratar de uma gramínea utilizada na formação de palhada, o maior tempo de permanência de seus resíduos se deve a sua alta relação $\mathrm{C} / \mathrm{N}$, proporcionando maior resistência à decomposição e uniformidade de distribuição sobre o solo (Oliveira et al., 2002).

Com referência às profundidades avaliadas, a profundidade de 0-10 cm apresentou valor médio de MO de 46,61 $\mathrm{g} \mathrm{kg}^{-1}$, valor este significativamente superior ao da profundidade de 10-20 $\mathrm{cm}$, com teor médio de $36,61 \mathrm{~g} \mathrm{~kg}^{-1}$. Esta tendência é considerada normal nos sistemas de plantio direto, uma vez que a deposição dos tecidos vegetais aéreos na superfície condiciona maior concentração de MO nos primeiros centímetros do solo, graças ao seu não revolvimento (Hernani et al., 1999).

Tais resultados corroboram com os encontrados por Costa et al. (2006) que também detectaram diferença estatística entre os teores de MO nas camadas de 0-10 e 10-20 cm em parcelas sob sistema de plantio direto em Latossolos no DF e atribuíram a maior concentração de MO nas camadas superficiais à manutenção dos restos vegetais na superfície do terreno.

Com base neste cenário, fica evidente a correlação positiva entre a CTC e a MO detectados no presente estudo. Observase incremento da CTC, conforme a elevação dos teores de MO, particularmente entre as profundidades avaliadas, graças ao não revolvimento do solo e à permanência dos resíduos culturais na sua superfície.

Falleiro et al. (2003) verificaram, estudando a influência dos sistemas de preparo do solo nas suas propriedades químicas e físicas, incrementos nos valores da CTC na camada superficial em sistema de plantio direto, acompanhando os aumentos de MO. Resultados análogos obtiveram Araújo et al. (2007) que detectaram tendências similares na variação da CTC e da MO no Latossolo avaliado do DF, onde os valores superiores foram verificados nas camadas mais superficiais estudadas (0-5 e 5-10 $\mathrm{cm})$. Os autores observaram redução significativa da CTC, assim como da $\mathrm{MO}$ em relação à profundidade em solos sob diferentes usos e sob cerrado nativo.

Os valores obtidos para respiração basal (Rmic) apresentaram grande variação entre as duas áreas estudadas, sendo de 13,71

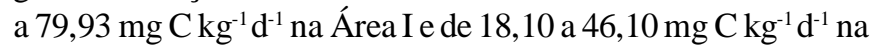
Área II. A análise estatística isolada dos tratamentos (Área I e Área II) e profundidades (0-10 e 10-20 cm), mostrou diferença significativa a $1 \%$ no teste de Tukey, para a profundidade.

As Áreas I e II apresentaram, respectivamente, valores médios de Rmic de 37,49 e 30,72 mg C kg ${ }^{-1} \mathrm{~d}^{-1}$, considerados sustentáveis pelos parâmetros sugeridos por Goedert (2005) para Latossolos tropicais, devendo estar acima de $10 \mathrm{mg} \mathrm{C} \mathrm{kg}^{-1} \mathrm{~d}^{-1}$.

Ante as elevadas taxas de Rmic detectadas, sugere-se que este fato esteja relacionado à influência do sistema de plantio direto (PD) adotado nas áreas em estudo. No plantio direto, aumentos na respiração do solo têm sido justificados pelo acúmulo de matéria orgânica rica em frações lábeis na superfície (Vargas \& Scholles, 2000).

Como nos manejos em estudo, ou seja, o sistema de plantio direto com rotação (Área I) e com sucessão (Área II), os valores médios de Rmic detectados não foram considerados estatisticamente distintos, constata-se que a Rmic não foi sensível aos diferentes manejos do sistema de plantio direto avaliados nas Áreas I e II, fato detectado pelo trabalho conduzido por D'Andréa et al. (2002), no qual os autores verificaram que a Rmic não variou significativamente frente aos diferentes tipos de manejo dos solos, particularmente entre os sistemas de PD e Plantio Convencional (PC). Assim, não tendo este atributo respondido diferentemente a sistemas tão contrastantes (PD e PC), pode-se justificar a falta de influência dos diferentes tipos de manejo estudados (PD com rotação e PD com sucessão) sobre a Rmic.

Costa et al. (2006) notaram, ao comparar a Rmic em sistemas de preparo convencional e plantio direto, que os valores mais elevados foram detectados em um tratamento sob sistema de plantio direto, provavelmente em resposta à maior adição de restos culturais com maior relação $\mathrm{C} / \mathrm{N}$.

Em relação às profundidades estudadas, os teores médios de Rmic foram de $26,22 \mathrm{mg} \mathrm{C} \mathrm{kg}^{-1} \mathrm{~d}^{-1}$ na camada de $0-10 \mathrm{~cm}$ e de $40,06 \mathrm{mg} \mathrm{C} \mathrm{kg}^{-1} \mathrm{~d}^{-1}$ na camada de $10-20 \mathrm{~cm}$. 
O fato da profundidade de $0-10 \mathrm{~cm}$ apresentar valor médio de MO mais elevado quando comparada com o da profundidade subjacente, poderia fornecer indícios de uma Rmic menos expressiva, tornando possível uma decomposição microbiana menos efetiva, preservando mais MO nesta camada. É provável que uma atividade microbiana menos atuante na profundidade mais superficial avaliada $(0-10 \mathrm{~cm})$, responsável pela decomposição da MO, tenha promovido uma liberação mais discreta de $\mathrm{CO}_{2}$.

Em se tratando de áreas com cerca de 15 anos sob PD, como as do presente estudo, a hipótese de conversão de $\mathrm{C}$ orgânico do solo em $\mathrm{CO}_{2}$, evidenciado pelas altas taxas de Rmic verificadas, pode ser considerada. Este mecanismo de perdas de C orgânico para a atmosfera refletiria em menor substrato para atuação dos microorganismos e consequentes restrições na imobilização de C orgânico.

Comportamento similar da Rmic frente às diferentes profundidades foi observado nos estudos conduzidos por D’Andréa et al. (2002) ao avaliarem alterações nos atributos biológicos do solo desencadeados por diferentes tipos de manejo agrícola. Os autores detectaram valores médios de Rmic mais elevados em camadas mais profundas do solo em comparação com as camadas superficiais analisadas.

A biomassa microbiana apresentou, assim como os valores de Rmic, elevada variabilidade com valores oscilando de 38,78 a $138,10 \mathrm{mg} \mathrm{C} \mathrm{kg}^{-1}$ na Área I e de 27,06 a 217,36 mg C kg-1 na Área II, nas diversas repetições. A análise estatística isolada dos tratamentos (Área Ie Área II) e profundidades $(0-10 \mathrm{~cm} \mathrm{e}$ $10-20 \mathrm{~cm}$ ) mostrou diferença significativa a $1 \%$ no teste de Tukey, para tratamentos e a $5 \%$ para profundidades.

A diferença significativa constatada foi verificada entre os valores médios do Cmic das Áreas I e II, sendo esses 74,98 e $126,99 \mathrm{mg} \mathrm{C} \mathrm{kg}^{-1}$. Tais valores estão abaixo de $200,00 \mathrm{mg} \mathrm{C} \mathrm{kg}^{-1}$, sendo considerados, então, não sustentáveis, conforme conjunto de valores de parâmetros de QS considerados sustentáveis propostos por Goedert (2005) para Latossolos tropicais.

Tal diferença pode ser justificada pela forma de deposição de resíduos orgânicos no solo da Área II, de cultivo mais intenso que, aliada às altas taxas de Rmic, favoreceu a maior conversão do C orgânico em Cmic. Em geral, o incremento da biomassa microbiana está relacionado ao aumento do conteúdo de MO do solo, de acordo com Rezende et al. (2004), o que não foi verificado neste trabalho. É provável que o maior valor médio de Cmic constatado na Área II tenha resultado principalmente da decomposição mais efetiva dos tecidos radiculares das culturas adotadas no sistema de PD com sucessão.

Possivelmente, as taxas de mineralização estariam superando as de imobilização de Carbono pela biomassa microbiana, colaborando com a redução do Cmic nas áreas estudadas. As altas taxas de Rmic detectadas em ambas as áreas podem ser explicadas pela perda de Carbono (C) orgânico do solo, que estaria sendo rapidamente convertido em $\mathrm{Cmic}$ e sendo perdido para a atmosfera na forma de $\mathrm{CO}_{2}$. Sempre que determinada biomassa microbiana se torna mais eficiente, menos carbono é perdido como $\mathrm{CO}_{2}$ pela respiração e uma fração significativamente de Carbono é incorporada à biomassa microbiana (Insam \& Domsch, 1988).
Com relação às profundidades avaliadas, os valores médios de Cmic foram de 133,81 e 77,06 mg $\mathrm{C} \mathrm{kg}^{-1}$, nas camadas de 0-10 e 10-20 cm, respectivamente. Tais resultados são compatíveis com as observações efetuadas por Ferreira et al. (2007) ao avaliarem a dinâmica do Cmic em diferentes sistemas de manejo; esses autores verificaram que no solo sob sistema de PD os teores de Cmic decresceram das camadas mais superficiais para as mais profundas e de forma mais acentuada do que no solo sob sistemas de cultivo convencionais.

Os valores das correlações entre os atributos de qualidade do solo (QS) avaliados estão dispostos na Tabela 2.

Tabela 2. Matriz de correlações de Pearson para os indicadores de QS avaliados

\begin{tabular}{ccccccc}
\hline Atributos $^{*}$ & GF & Ds & CTC & MO & Rmic & Cmic \\
GF & 1 & & & & & \\
Ds & $-0,160$ & 1 & & & & \\
CTC & 0,141 & $-0,406$ & 1 & & & \\
M0 & 0,168 & $-0,340$ & 0,874 & 1 & & \\
Rmic & 0,189 & 0,205 & $-0,381$ & $-0,297$ & 1 & \\
Cmic & 0,107 & $-0,431$ & 0,562 & 0,369 & $-0,375$ & 1 \\
\hline
\end{tabular}

$\left({ }^{*}\right) \mathrm{GF}=$ Grau de Floculação, Ds = Densidade do solo; CTC = Capacidade de Troca Catiônica; M0 = Matéria Orgânica; Rmic = Respiração; Basal Microbiana; Cmic = Carbono da Biomassa Microbiana

As correlações de Pearson obtidas entre os atributos de QS avaliados nas Áreas I e II estudadas demonstram que houve uma relação altamente significativa e direta entre a capacidade de troca catiônica (CTC) e a matéria orgânica (MO) dos Latossolos estudados, da ordem de 87,4\% (Tabela 2).

A correlação positiva da MO com a CTC, já constatada e discutida no presente trabalho, é justificável, já que em solos tropicais, com predominância de argilominerais de baixa atividade e sesquióxidos, a fração orgânica contribui com a maior proporção das cargas negativas (Barbosa \& Lacerda, 2009, Campos et al., 2010). Como a maior proporção da CTC de solos com argilas de baixa atividade é originária de sua fração orgânica, estava previsto que as tendências registradas para a MO se mantivessem para a CTC, confirmando os relatos de Costa et al. (2006).

Resultados similares foram relatados por Araújo et al. (2007) que, ao investigar a qualidade de um solo sob diferentes usos, detectaram uma correlação significativa e direta entre a MO e a CTC. Similarmente, Netto (2009) verificou uma correlação altamente significativa entre a MO e a CTC em Latossolos do DF sob pastagens com diferentes períodos de uso.

\section{CONCLUSÕES}

1. O grau de floculação (GF), capacidade de troca catiônica (CTC) e respiração basal microbiana (Rmic) não mostraram variação nos sistemas de cultivo estudados - plantio direto com rotação de culturas (Área I) e plantio direto com sucessão de culturas (Área II) - indicando a reduzida sensibilidade desses atributos frente aos diferentes tipos de manejo avaliados.

2. A densidade do solo (Ds), matéria orgânica (MO) e carbono da biomassa microbiana (Cmic) foram influenciados pelos sistemas de cultivo investigados, evidenciando a significativa 
sensibilidade desses atributos em relação aos manejos adotados.

3. Os atributos químicos de qualidade do solo, MO e CTC, apresentaram correlação positiva e significativa, na qual os maiores teores de ambos os atributos foram verificados na profundidade de $0-10 \mathrm{~cm}$ das áreas estudadas.

\section{LITERATURA CITADA}

Alef, K; Nannipierre, P. Methods in applied soil microbiology and biochemistry. London: Academic Press, 1995. 576p.

Araújo, R.; Goedert, W. J.; Lacerda, M. P. C. Qualidade de um solo sob diferentes usos e sob Cerrado nativo. Revista Brasileira de Ciência do Solo, v.31, p.1099-1108, 2007.

Barbosa, I. O.; Lacerda, M. P. C. Relações pedomorfogeológicas nas Chapadas Elevadas do Distrito Federal. Revista Brasileira de Ciência do Solo, v.33, p.273 283, 2009.

Bayer, C.; Mielniczuk, J.; Martin-Neto, L.; Ernani, P. R. Stocks and humification degree of organic matter fractions as afeccted by no-tillage on a subtropical soil. Plant Soil, v.238, p.133-140, 2002.

Bayer, C.; Spagnollo, E.; Wildner, L. P.; Ernani, P. R.; Albuquerque, J.A. Incremento de carbono e nitrogênio num Latossolo pelo uso de plantas estivais para cobertura do solo. Ciência Rural, v.33, p.469-475, 2003.

Campos, P. M.; Lacerda, M. P. C.; Silva, C. L.; Sá, M. A. C de; Sousa, D. M. G. de. A drenagem interna como fator de diferenciação dos Latossolos do Distrito Federal. Pesquisa Agropecuária Brasileira, v.45, p.306-314, 2010.

Canellas, L. P.; Velloso, A. C. X.; Marciano, C. R.; Ramalho, J. F. G. P.; Rumjanek, V. M.; Rezende, C. E.; Santos, G. A. Propriedades químicas de um Cambissolo cultivado com cana-de-açúcar, com preservação do palhiço e adição de vinhaça por longo tempo. Revista Brasileira de Ciência do Solo, v.27, p.935-944, 2003.

Carneiro, M. A. C; Souza E. D. de; Reis, E. F. dos; Pereira, H. S.; Azevedo, W. R. de. Atributos físicos, químicos e biológicos de solo de Cerrado sob diferentes sistemas de uso e manejo. Revista Brasileira de Ciência do Solo, v.33, p.147-157, 2009.

Carneiro, P. J. R.; Maldaner, V. I.; Alves, P. F.; Queirós, I. C. de; Mauriz, T. V.; Pacheco, R. F. Evolução do uso da água na bacia do rio Preto no Distrito Federal. Espaço \& Geografia, v.10, p.325-353, 2007.

Carvalho Jr., I. A.; Fontes, L. E. F.; Costa, L. M. Modificações causadas pelo uso e a formação de camada compactada e, ou adensamento em Latossolo Vermelho-Escuro textura média, na região dos cerrados. Revista Brasileira de Ciência do Solo, v.22, p. 505-514, 1998.

CODEPLAN - Companhia de Planejamento do Distrito Federal Atlas do Distrito Federal. Brasília: Secretaria de Educação e Cultura/CODEPLAN. v.1. 1984. 78p.

Costa, E. A.; Goedert, W. J.; Sousa, D. M. G. Qualidade de solo submetido a sistemas de cultivo com preparo convencional e plantio direto. Pesquisa Agropecuária Brasileira, v.41, p.1185-1191, 2006.
Costa, F. S.; Bayer, C.; Zanatta, J. A.; Mielniczuk, J. Estoque de carbono orgânico no solo e emissões de dióxido de carbono influenciadas por sistemas de manejo no sul do Brasil. Revista Brasileira de Ciência do Solo, v.32, p.323-332, 2008.

D’Andréa, A. F.; Silva, M. L. N.; Curi, N.; Siqueira, J. O.; Carneiro, M. A. C. Atributos biológicos indicadores da qualidade do solo em sistemas de manejo na região do Cerrado no sul do estado de Goiás. Revista Brasileira de Ciência do Solo, v.26, p.913-923, 2002.

Doran, J. W.; Parkin, T. B. Defining and assessing soil quality. In: Doran, J. W.; Coeman, D. C.; Bezdicek, D. F; Stewart, B. A. (ed.) Defining soil quality for sustainable environment. Madison, Soil Science Society of America, v.35, p.3-21, 1994.

EMBRAPA- Empresa Brasileira de Pesquisa Agropecuária. Levantamento de reconhecimento dos solos do Distrito Federal. Rio de Janeiro: SNLCS, 1978. 455p. Boletim Técnico, n. 53

EMBRAPA - Empresa Brasileira de Pesquisa Agropecuária Centro de Nacional de Pesquisa de Solos. Manual de métodos de análises de solos. 2.ed. Rio de Janeiro: EMBRAPA, 1997. 212p.

EMBRAPA - Empresa Brasileira de Pesquisa Agropecuária. Centro Nacional de Pesquisa de Solos. Sistema Brasileiro de Classificação de Solos. 2.ed. Rio de Janeiro: EMBRAPA, 2006. 306p.

Falleiro, R. M.; Souza, C. M.; Silva, C. S. W.; Sediyama, C. S.; Silva, A. A.; Fagundes, J. L. Influência dos sistemas de preparo nas propriedades químicas e físicas do solo. Revista Brasileira de Ciência do Solo, v.27, p.1097-1104, 2003.

Ferreira, E. A. B.; Resck, D. V. S.; Gomes, A. C.; Ramos, M. L. G. Dinâmica do Carbono da biomassa microbiana em cinco épocas do ano em diferentes sistemas de manejo do solo do Cerrado. Revista Brasileira de Ciência do Solo, v.31, p.16251635, 2007.

Goedert, W. J. Qualidade do solo em sistemas de produção agrícola. In: Congresso Brasileiro de Ciência do Solo, 30., 2005, Recife. Anais... Recife: SBCS, 2005. CD Rom

Hernani, L. C.; Kurihara, C. H.; Silva, W. M. Sistemas de manejo de solo e perdas de nutrientes e matéria orgânica por erosão. Revista Brasileira de Ciência do Solo, v.23, p.145-154, 1999.

Insam, H.; Domsch, K. H. Relationship between soil organic carbon and microbial biomass on chronosequences of reclamation sites. Microbial Ecology, v.15, p.177-188, 1988.

Lourente, E. R. P.; Mercante, F. M.; Alovisi, A. M. T.; Gomes, C. F.; Gasparini, A. S.; Nunes, C. M. Atributos microbiológicos, químicos e físicos de solo sob diferentes sistemas de manejo e condições de Cerrado. Pesquisa Agropecuária Tropical, v.41, p.20-28, 2011.

Netto, I. T. P. Qualidade física e química de um Latossolo Vermelho-Amarelo sob pastagens com diferentes períodos de uso. Revista Brasileira de Ciência do Solo, v.33, p.14411448, 2009.

Oliveira, T. K. de; Carvalho, G. J. de; Moraes, R. N. de S. Plantas de cobertura e seus efeitos sobre o feijoeiro em plantio direto. Pesquisa Agropecuária Brasileira, v.37, p.1079-1087, 2002. 
Rangel, O. J. P.; Silva, C. A. Estoques de carbono e nitrogênio e frações orgânicas de Latossolo submetido a diferentes sistemas de uso e manejo. Revista Brasileira de Ciência do Solo, v.31, p.1609-1623, 2007.

Reichert, J. M.; Suzuki, L. E. A. S.; Reinert, D. J.; Horn, R.; Hakansson, I. Reference bulk density and critical degreeof-compactness for no-till crop prodution in subtropical highly weathered soils. Soil and Tillage Research, v.102, p.242-254, 2009.

Reinert, D. J.; Albuquerque, J. A.; Reichert, J. M.; Aita, C.; Andrada, M. M. C. Limites críticos de densidade do solo para o crescimento de raízes de plantas de cobertura em Argissolo Vermelho. Revista Brasileira de Ciência do Solo, v.32,p.1805-1816, 2008.

Rezende, L. A.; Assis, L. C.; Nahas, E. Carbon, nitrogen and phosphorous mineralization in two soils amended with distillery yeast. Bioresource Technology, v.94, p.159-167, 2004.

Santos, R. D.; Lemos, R. C.; Santos, H. G.; Ker, J. C.; Anjos, L. H. C. Manual de descrição e coleta de solo no campo. 5.ed. Viçosa, Sociedade Brasileira de Ciência do Solo, 2005. 100p.
Silva, M. L. N.; Curi, N.; Blancaneaux, P. Sistemas de manejoe qualidade estrutural de Latossolo Roxo. Pesquisa Agropecuária Brasileira, v.35, p.2485-2492, 2000.

Silva, R. H.; Rosolem, C. A. Crescimento radicular de espécies utilizadas como cobertura decorrente da compactação do solo. Revista Brasileira de Ciência do Solo, v.25, p.253-260, 2001.

Silva, V. R.; Reichert, J. M.; Reinert, D. J. Variabilidade espacial da resistência do solo à penetração em plantio direto. Ciência Rural, v.34, p.399-406, 2004.

Silveira, P. M.; Stone, L. F. Sistemas de preparo do solo e rotação de culturas na produtividade de milho, soja e trigo. Revista Brasileira de Engenharia Agrícola e Ambiental, v.7, p.240-244, 2003.

Vance, E. D.; Brookes, P. C.; Jenkinson, D. S. An extraction method for measuring soil microbial biomass C. Soil Biology and Biochemistry, v.19, p.703-707, 1987.

Vargas, L. K.; Scholles, D. Biomassa microbiana e produção de $\mathrm{C}-\mathrm{CO}_{2}$ e $\mathrm{N}$ mineral de um Podzólico Vermelho-Escuro submetido à diferentes sistemas de manejo. Revista Brasileira de Ciência do Solo, v.24, p.35-42, 2000. 